\title{
QUANTITATIVE RADIOCARDIOGRAPHY IN PATIENTS WITH PATENT DUCTUS ARTERIOSUS
}

\author{
TADAshi Matsumura, M.D.
}

\begin{abstract}
Analytical models of the analog computer simulation method of radiocardiogram (RCG) were revised to obtain quantitative hemodynamic evaluations in patent ductus arteriosus (PDA). The theoretical and technical aspects are herein outlined, and the effects of clinical application discussed. Twenty-six patients with a left-to-right PDA shunt were studied by the revised RCG models, and the results were compared with oxymetric or echocardiographic data. Between RCG and oxymetry, the systemic blood flow (SBF) findings agreed well $(r=0.91)$, but in oxymetry, the pulmonary blood flow (PBF) findings were generally seen greater than in RCG $(r=0.81)$, and the oxymetric shunts appeared larger than in RCG $(r=0.75)$. This is because oxymetry cannot avoid the direct effects of the uneven partition of shunt flow to the lungs, whereas RCG can, in addition, measure the mean PBFs and SBFs. RCG may thus be said to be superior to oxymetry in assessing PDA shunts. Furthermore, RCG can estimate the mean left and right heart volumes (LHV and RHV) at the same time; the RCG LHV was found to correspond to the echocardiographic left ventricular end-diastolic volume (LVEDV) $(r=0.89)$. Moreover, the obtained relation between the RHV/LHV (Y) and the shunt ratio $(\mathrm{X})$ proved to be the same that calculated theoretically $(\mathrm{Y}=-\mathrm{X}+1.0)$ in uncomplicated patients. Patients not presenting this relation may be assumed to suffer some condition complicating the PDA. In effect, the analog computer simulation method of RCG is a unique non-invasive means of obtaining quantitative analyses in PDA and in other congenital shunt diseases as well.
\end{abstract}

$\mathbf{T}$ $\mathrm{HE}$ incidence of PDA, one of the most prevalent congenital heart diseases with a left-to-right (L-R) shunt, makes it important to establish an accurate and easy technique for assessing the hemodynamics of this disease without resorting to the traumatic procedures of cardiac catheterization. Pulmonary time activity curves recorded by a single probe or a gamma camera have been utilized for the quantitation of

\section{Key Words:}

Patent ductus arteriosus

Radiocardiography

Analog computer simulation

Oxymetry

Incomplete mixing intracardiac L-R shunts! ${ }^{1-4}$ In patients with PDA, however, these techniques do not permit accurate quantitation of the shunt because the partition of the shunt flow to the lungs is unequal, and different shunt ratios may be calculated for each lung!, 1,5 The problem of the differing partition is difficult to solve even in the oxymetric evaluation by cardiac catheterization.

The analog simulation method of RCG has been also utilized for the analysis of PDA shunts. This method enables a more reasonable PDA evaluation since it can measure the average PBF regardless of the unevenness of flow distribution. However, in the absence of RCG models for extracardiac shunts, PDA has hitherto been

(Received March 7, 1984; accepted September 11, 1984)

Cardiovascular Division, Tenri Hospital, Nara, Japan

Mailing address: Tadashi Matsumura, M.D., Cardiovascular Division, Tenri Hospital, Mishima-cho 200, Tenri, Nara 632, Japan 
PATIENT

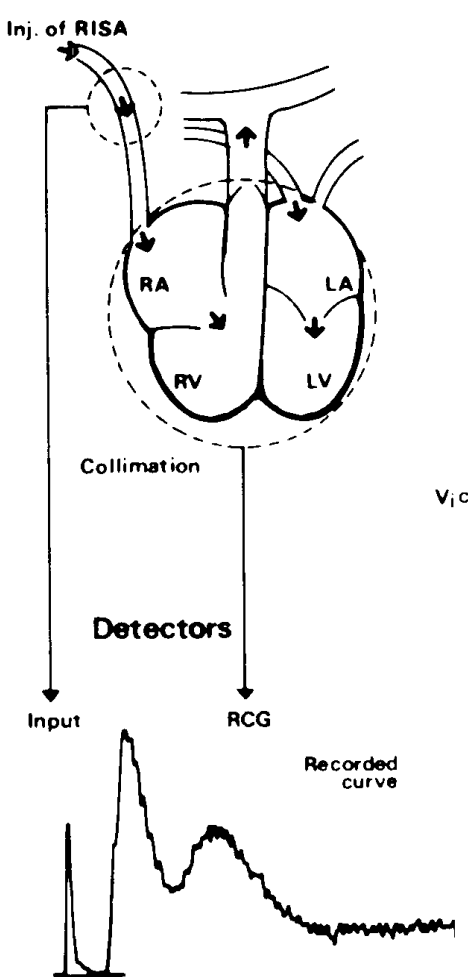

MODEL
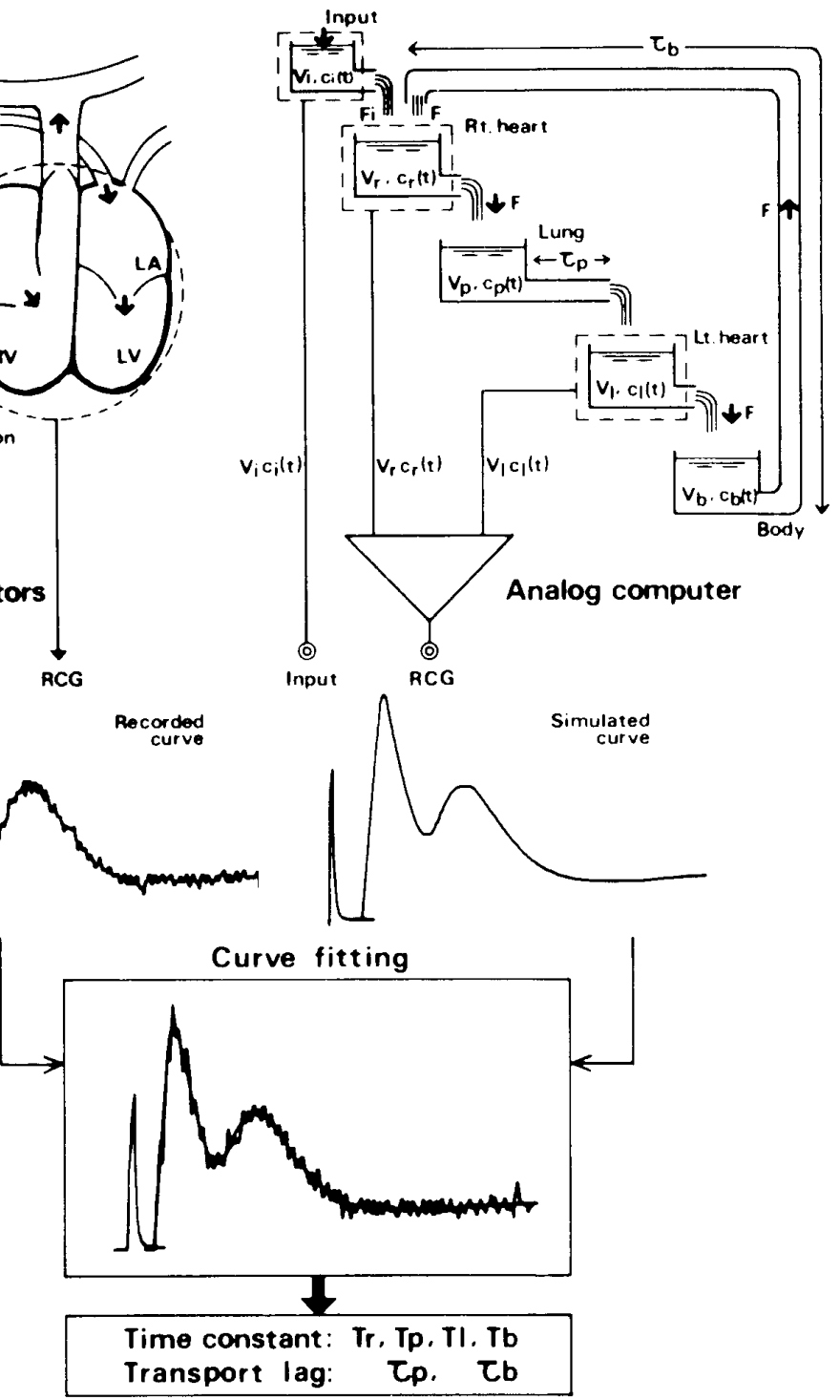

Fig.1. Schematic expression of analog computer simulation method of RCG. conveniently analyzed by using the intracardiac shunt models, a practice leading to errors in the estimation of the LHV. Recently, by revision of the existing models, we could obtain more suitable mathematical models for the extracardiac shunts, and were thus able to rectify the fault.

In this paper, the entire mathematical models are presented and the clinical application of our method to PDA patients is discussed.

Analysis of Radiocardiogram by Analog Computer Simulation ${ }^{7}$

The analog computer simulation method of RCG is a curvefitting method (Fig. 1). A simu- lated RCG, an output curve of the computer, is projected on and fitted with the measured one by adjusting the parameters described below. The mathematical models presented here were developed with consideration to the circulatory system from the hydrodynamic standpoint. The entire circulatory system is divided into four compartments: Right heart, lung, left heart, and body (systemic circulation). The right and left hearts are supposed as mixing chambers with each corresponding atrium and ventricle combined. It is assumed that the flow and volume of each compartment remain constant at any one time (t). Figure 2 shows a simplified cardiovascular system applied in the models. In case of 


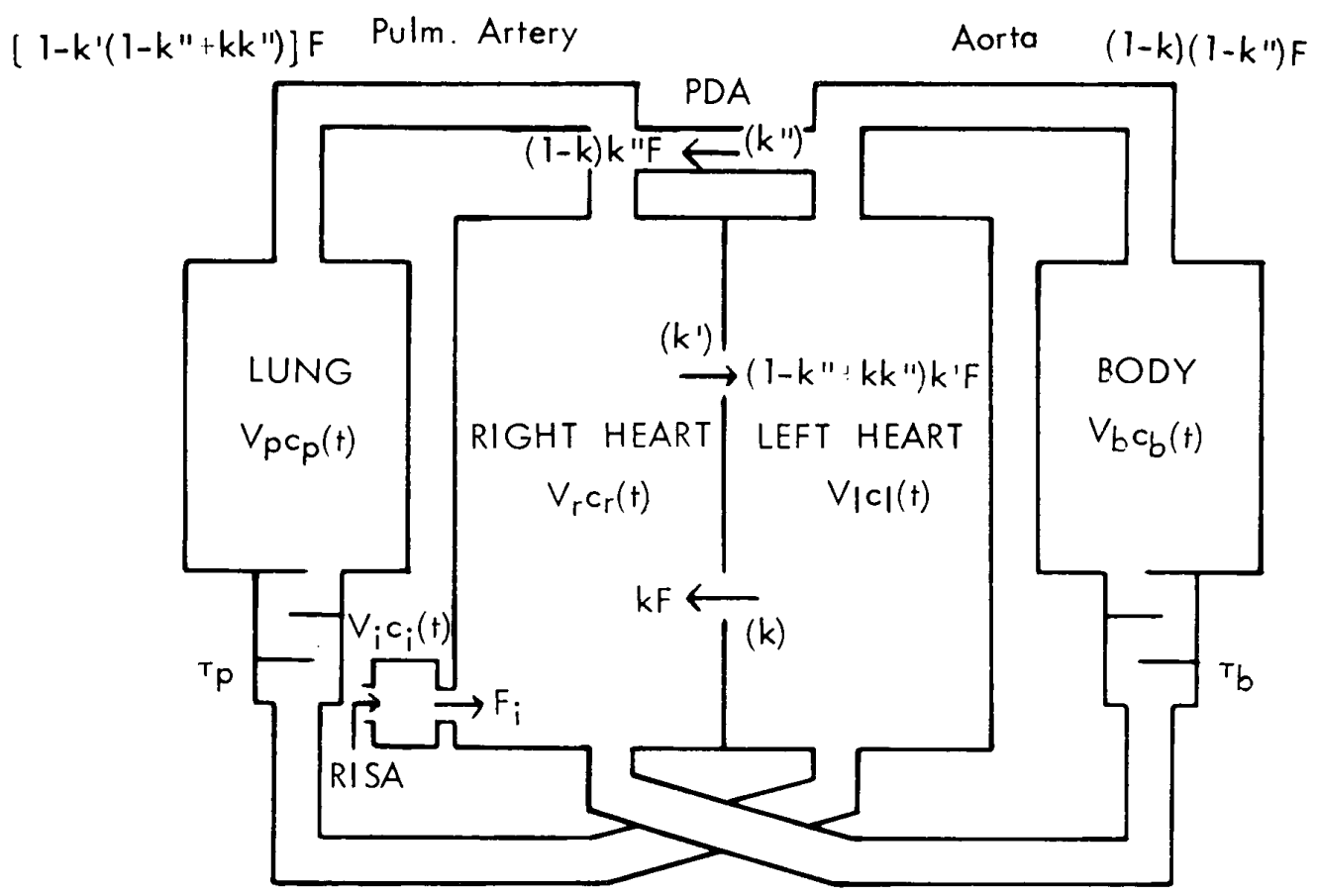

Fig.2. Simplified model of the circulatory system (see text). The subscripts $r, p, 1, b$ and $i$ denote the right heart, the lung, the left heart, the body and the injection compartment, respectively.

(a)

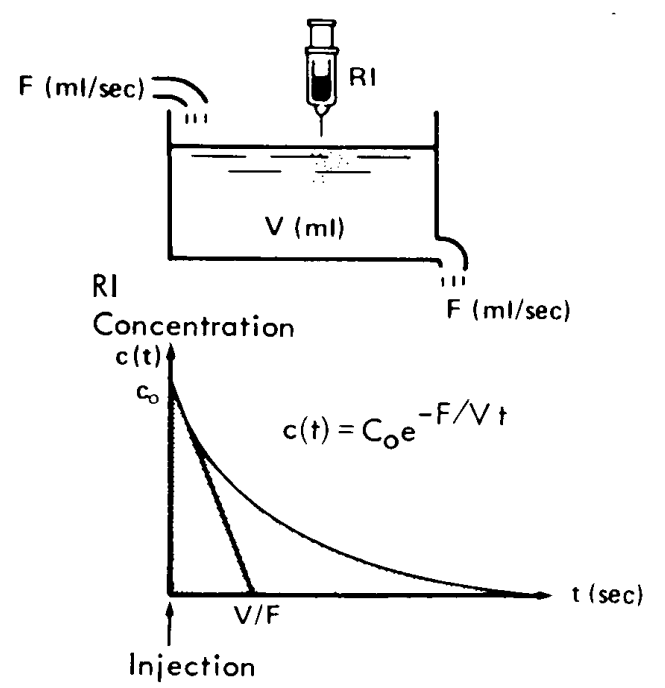

Mean Transit Time (b)

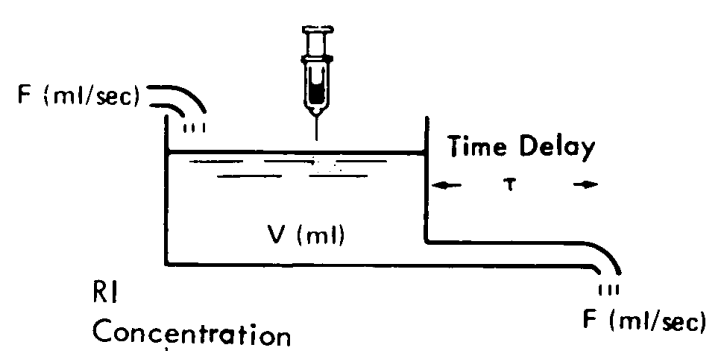

Concentration

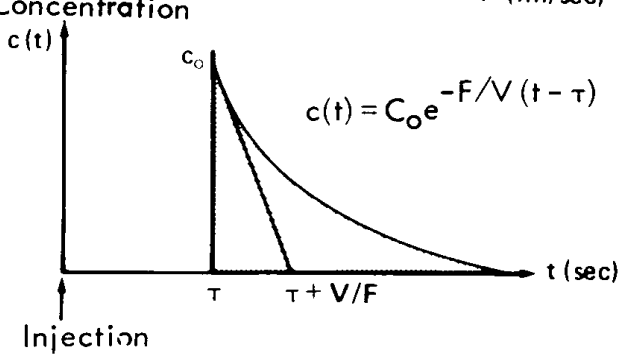

Injection

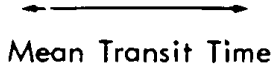

Fig.3. Characteristics of subsystems.

(a): right and left hearts, (b): lung and body

intracardiac shunts, the shunting blood runs from the left to the right with a ratio of $k$, and from the right to the left with a ratio of $k$ ' if a reverse shunt exists. PDA is known as a direct connection between the aorta (Ao) and the pulmonary artery (PA) with an extracardiac shunt ratio k". 


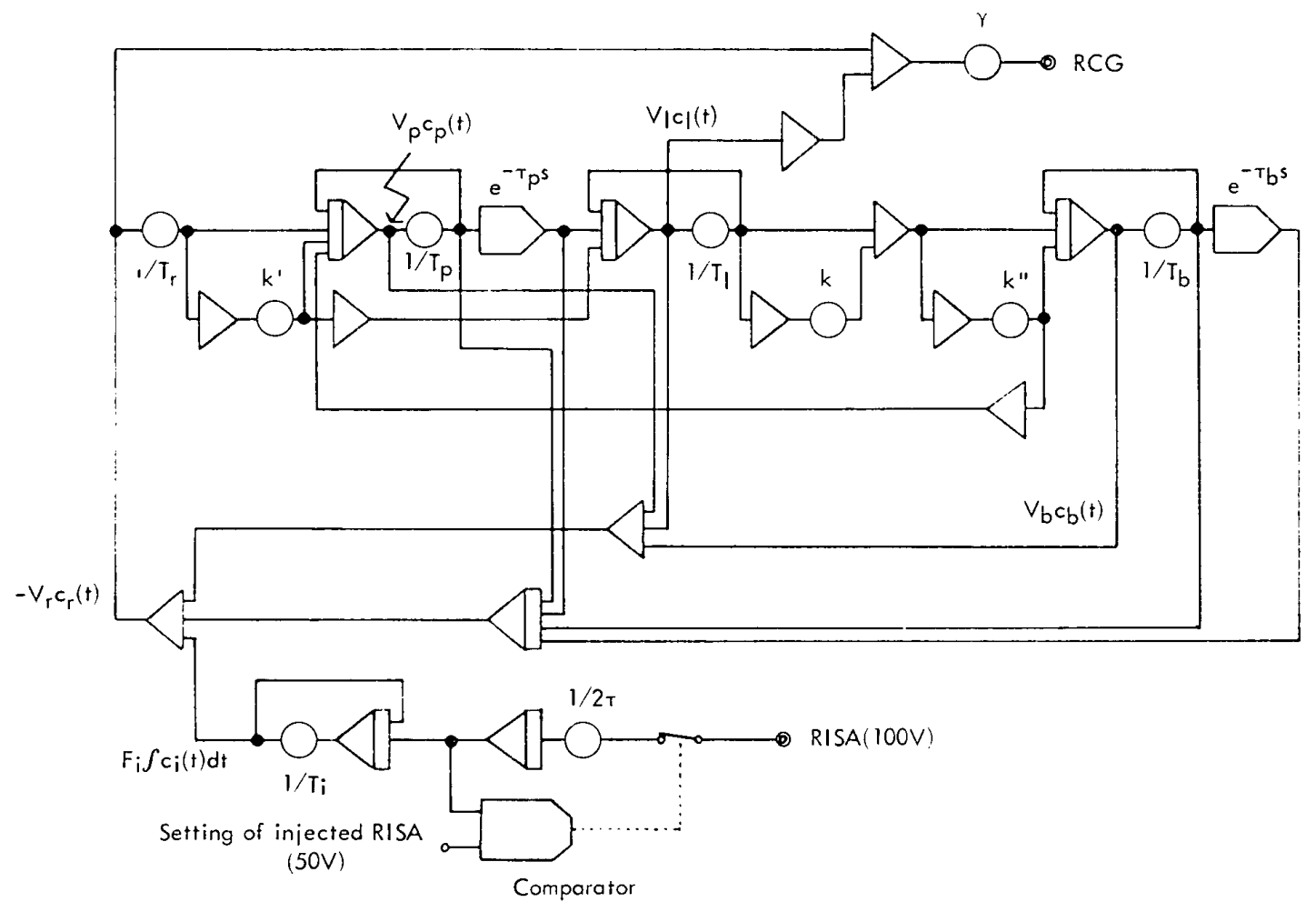

Fig.4. Analog computer simulation circuit. This circuit contains 12 parameters: $\gamma=$ gain in RCG; $\tau=$ duration of injection; $\mathrm{T}=$ time constant of each compartment; $\tau_{\mathrm{p}}$ and $\tau_{\mathrm{b}}=$ transport time lags in the lung and body; $k, k^{\prime}$ and $k "=$ ratios of intra- and extracardiac shunts

In Fig. 2, c (t) $(\mu \mathrm{Ci} / \mathrm{ml})$ stands for a concentration of injected tracer; $\mathrm{F}(\mathrm{ml} / \mathrm{sec})$ and $\mathrm{V}(\mathrm{ml})$ stand for mean blood flow and volume.

As for the subsystem to be considered as a mixing chamber like the right or the left heart, it is simply prescribed as a first order system by volume and flow; indicator clearance from the chamber is assumed to follow a single exponential decline. In that case, the time constant $(\mathrm{V} / \mathrm{F})$ also represents the mean transit time (MTT) (Fig. 3-a). On the other hand, the lung or the body, consisting of many vascular constructions, is assumed to be a mixing chamber with a transport time lag $\tau$ (sec), in which case the MTT is given by the time constant plus the time lag $(\mathrm{V} / \mathrm{F}+\tau)$ (Fig. 3-b).

It can be seen that this simplification will facilitate and simplify the overall picture of the cardiovascular hemodynamics.

\section{Mathematical Models and Analog Simulation Circuit of the Circulatory System}

A known quantity $(\mathrm{I} \mu \mathrm{Ci})$ of radionuclide tracer is rapidly injected into the blood circulation through the antecubital vein. Since RCG represents a passage of the tracer over a very short period through the heart, the quality of the injected bolus has great influences on its pattern. So, in our models, care is taken about this point; that is, an additional small mixing chamber is taken into account for the transport process of the injection compartment from which the tracer comes into the right atrium. If we indicate the mean blood volume, mean blood flow, tracer concentration at time $t$, and a rate of injection with $\mathrm{V}_{\mathrm{i}}(\mathrm{t}), \mathrm{F}_{\mathrm{i}}, \mathrm{c}_{\mathrm{i}}(\mathrm{t})$, and $\mathrm{i}(\mathrm{t})$, respectively, the mathematical expression of this chamber is:

$\mathrm{V}_{\mathrm{i}} \mathrm{c}_{\mathrm{i}}(\mathrm{t})=\int \mathrm{i}(\mathrm{t}) \mathrm{dt}-\mathrm{F}_{\mathrm{i}} \int \mathrm{c}_{\mathrm{i}}(\mathrm{t}) \mathrm{dt}$

Assuming that injection is made at a constant speed in time $\tau$,

$$
\mathrm{i}(\mathrm{t})=\left(\begin{array}{cc}
1 / \tau, & 0 \leqslant \mathrm{t} \leqslant \tau \\
0, & \mathrm{t}>\tau
\end{array}\right.
$$

and

$$
\int \mathrm{i}(\mathrm{t}) \mathrm{dt}=\mathrm{I} .
$$

In equation (1), no recirculation is presumed because $\tau$ is too short compared with the total measuring time of RCG for the injected tracer to reappear in this compartment within $0 \leqslant \mathrm{t} \leqslant \tau$.

Provided that the injected tracer is instantaneously mixed with blood in each compartment, the transportation of the tracer can be represented as follows: 
TABLE I NORMAL RANGES IN RCG PARAMETERS

\begin{tabular}{|c|c|c|}
\hline Cardiac index (C.I) & $2.96-5.82 \mathrm{~L} / \mathrm{min} / \mathrm{m}^{2}$ & \\
\hline Stroke index (S.I) & $44-81 \mathrm{ml} /$ beat $/ \mathrm{m}^{2}$ & \\
\hline Mean blood turn-over rate $(\mathrm{F} / \mathrm{V})$ & $1.13-2.26 \mathrm{~min}^{-1}$ & \\
\hline \multicolumn{3}{|l|}{ Mean transit time } \\
\hline Lung & $3.2-5.9 \mathrm{sec}$ & \\
\hline Body & $20.7-41.7 \mathrm{sec}$ & \\
\hline Right heart & $1.4-3.1 \mathrm{sec}$ & \\
\hline Left heart & $1.4-3.2 \mathrm{sec}$ & \\
\hline \multicolumn{3}{|l|}{ Blood volume } \\
\hline Lung & $230-390 \mathrm{ml} / \mathrm{m}^{2}$ & $(11.5 \pm 1.1 \%)$ \\
\hline Body & $1710-2390 \mathrm{ml} / \mathrm{m}^{2}$ & $(77.4 \pm 1.7 \%)$ \\
\hline Right heart & $110-190 \mathrm{ml} / \mathrm{m}^{2}$ & \multirow[b]{2}{*}{$(11.1 \pm 1.2 \%)$} \\
\hline Left heart & $110-200 \mathrm{ml} / \mathrm{m}^{2}$ & \\
\hline Circulating blood volume & $2.20-3.07 \mathrm{~L} / \mathrm{m}^{2}$ & $(100.0 \%)$ \\
\hline Right heartlleft heart ratio & $1.01 \pm 0.20$ & \\
\hline
\end{tabular}

Right heart:

$$
\begin{aligned}
V_{r} c_{r}(t)= & F_{i} \int c_{i}(t) d t+B \cdot F \int c_{b}\left(t-\tau_{b}\right) d t \\
& +k \cdot F \int c_{l}(t) d t-R \cdot F \int c_{r}(t) d t \ldots \\
& \\
V_{p} c_{p}(t)= & (1-k) \cdot R \cdot F \int c_{r}(t) d t \\
& +(1-k) \cdot k " \cdot F \int c_{l}(t) d t \\
& -P \cdot F \int c_{p}(t) d t \ldots \ldots . \ldots .
\end{aligned}
$$

Lung:

Left heart:

$$
V_{1} c_{l}(t)=P \cdot F \int c_{p}\left(t-\tau_{p}\right) d t+k^{\prime} \cdot R \cdot F \int c_{r}(t) d t
$$

Body:

$$
-F \int c_{1}(t) d t \ldots \ldots \ldots \ldots(6)
$$

$$
V_{b} c_{b}(t)=B \cdot F \int c_{l}(t)-B \cdot F \int c_{b}(t) d t \ldots
$$

where $B=(1-k) \cdot(1-k ")$

$$
\begin{aligned}
R & =B+k=1-k^{\prime}+k k^{\prime} \\
P & =\left(1-k^{\prime}\right) \cdot R+(1-k) \cdot k \\
& =1-\left(1-k^{\prime \prime}+k k^{\prime \prime}\right) \cdot k^{\prime} .
\end{aligned}
$$

$F_{i}$ is neglected in the outflow of the right heart because it is sufficiently small compared with F.

Thus, if a collimator covers only the entire heart and counts radioactivities from the right and left hearts at a same counting rate $(\gamma)$, the equation of RCG can be given by

$r(t)=\gamma \cdot\left[V_{r} c_{r}(t)+V_{1} c_{1}(t)\right]$

On the other hand, the total amount of injected radionuclide during time $t$ equals to the sum of its contents in four compartments. That is,

$$
\begin{aligned}
F_{i} \int c_{i}(t)= & V_{r} c_{r}(t)+V_{p} c_{p}(t)+V_{r} c_{r}(t) \\
& +V_{b} c_{b}(t)+P \cdot F \cdot\left[\int c_{p}(t) d t\right. \\
& \left.-\int c_{p}\left(t-\tau_{p}\right) d t\right]+B \cdot F \cdot\left[\int c_{b}(t) d t\right. \\
& \left.-\int c_{b}\left(t-\tau_{b}\right) d t\right] \ldots \ldots(9)
\end{aligned}
$$

Here, if we define the time constant $(\mathrm{T})$ of each compartment as $T_{r}=V_{r} /(R \cdot F), T_{p}=V_{p} /$ $(\mathrm{P} \cdot \mathrm{F}), \mathrm{T}_{1}=\mathrm{V}_{\mathrm{l}} / \mathrm{F}, \mathrm{T}_{\mathrm{b}}=\mathrm{V}_{\mathrm{b}} /(\mathrm{B} \cdot \mathrm{F})$, or $\mathrm{T}_{\mathrm{i}}=\mathrm{V}_{\mathrm{i}} / \mathrm{F}_{\mathrm{i}}$ we can obtain the analog simulation circuit illustrated in Fig. 4. This circuit has 12 parameters, and we can project a simulated RCG upon the measured one and fit them by adjusting these parameters. The practical techniques of this procedure have already been described elsewhere?, 8

When a simulation has been complished, the shunt ratio(s) (K, K', K"), time constants $\left(T_{r}\right.$, $\left.T_{p}, T_{1}, T_{b}\right)$, and transport time lags $\left(\tau_{b}, \tau_{p}\right)$ are determined. The MTTs of the four compartments are then given by

$\operatorname{MTT}_{\mathrm{r}}=\mathrm{T}_{\mathrm{r}}, \operatorname{MTT}_{\mathrm{p}}=\mathrm{T}_{\mathrm{p}}+\tau_{\mathrm{p}}, \mathrm{MTT}_{1}=\mathrm{T}_{1}$,

$\mathrm{MTT}_{\mathrm{b}}=\mathrm{T}_{\mathrm{b}}+\tau_{\mathrm{b}} \ldots \ldots \ldots \ldots \ldots$ (10)

In turn, the mean blood volumes are calculated as follows:

Right heart volume $(\mathrm{RHV})=\mathrm{R} \cdot \mathrm{F} \cdot \mathrm{MTT}_{\mathrm{r}}$

Pulmonary blood volume

$$
(\mathrm{PBV})=\mathrm{P} \cdot \mathrm{F} \cdot \mathrm{MTT}_{\mathrm{p}}
$$


Left heart volume $(\mathrm{LHV})=\mathrm{F} \cdot \mathrm{MTT}_{1}$

Body blood volume $(\mathrm{BBV})=\mathrm{B} \cdot \mathrm{F} \cdot \mathrm{MTT}_{\mathrm{b}}(11)$

Summing up these equations we can obtain

$\mathrm{RHV}+\mathrm{PBV}+\mathrm{LHV}+\mathrm{BBV}$

$=\mathrm{F} \cdot\left(\mathrm{R} \cdot \mathrm{MTT}_{\mathrm{r}}+\mathrm{P} \cdot \mathrm{MTT}_{\mathrm{p}}+\mathrm{MTT}_{1}+\mathrm{B} \cdot \mathrm{MTT}_{\mathrm{b}}\right)$

The left side of the equation represents simply the total of the circulating blood volumes (CBV) that can be measured separately, and the equation is replaced by

$$
\begin{aligned}
\mathrm{F}(\mathrm{ml} / \mathrm{sec})= & \mathrm{CBV} /\left(\mathrm{R} \cdot \mathrm{MTT}_{\mathrm{r}}+\mathrm{P} \cdot \mathrm{MTT}_{\mathrm{p}}\right. \\
& \left.+\mathrm{MTT}_{1}+\mathrm{B} \cdot \mathrm{MTT}_{\mathrm{b}}\right) \ldots . .
\end{aligned}
$$

The $\mathrm{PBF}$ and $\mathrm{SBF}$ are

$\operatorname{PBF}(\mathrm{ml} / \mathrm{sec})=\mathrm{P} \cdot \mathrm{F}$

$$
=\left[1-\left(1-k^{\prime \prime}+k k^{\prime \prime}\right) \cdot k^{\prime}\right] \cdot F
$$

$\operatorname{SBF}(\mathrm{ml} / \mathrm{sec})=\mathrm{B} \cdot \mathrm{F}=[(1-\mathrm{k}) \cdot(1-\mathrm{k} ")] \cdot \mathrm{F}$

Reverting to equations (11), the blood volume in every compartment can then be calculated.

Normal ranges of RCG parameters are tabulated in Table I?

\section{MATERIALS AND METHODS}

Patient profiles: Twenty-six patients with PDA ( 3 males and 23 females) whose diagnosis was confirmed by cardiac catheterization were studied. They ranged from 6 to 33 (mean 16.5) years of age. Among these, none had a reverse shunt but one revealed significant pulmonary regurgitation by pulmonary arteriography.

Radiocardiography: The RCG was tested within one week either before or after a catheterization study. The cardiac silhouette was drawn on the patient's chest wall referring to a plain chest X-ray and cardiac percussion dullness. A lead plate ( $1 \mathrm{~cm}$ thick) was placed caudal to the lung-liver border to eliminate back ground activities from the abdominal organs. A NaI crystal probe ( 3 inches in diameter) with a long $(20 \mathrm{~cm})$ cylindric collimator was placed right upon the precordial area. This manner of collimation was appropriate to our mathematical model. Another smaller probe $(2$ inches in diameter with a $5 \mathrm{~cm}$ length collimator) was oriented to the subclavian vein on the injection side to obtain an input curve of the radionuclide tracer and to check the quality of the injected bolus.

Radionuclide and injection technique: Iodide-13I labeled human serum albumin $\left({ }^{131} \mathrm{I}\right.$ HSA) was used. ${ }^{131}$ I-HSA was proven to be better than technetium-99m-HSA for the precise measurement of the CBV ${ }^{10}$ A dose of $0.5 \mu \mathrm{Ci} / \mathrm{kg}$ body weight (volume of the solution was 0.2 to $0.3 \mathrm{ml}$ ) was rapidly injected from the basilic vein according to the cuff releasing technique!l Injections with this method resulted in satisfactory studies in all patients.

Data aquisition: Signals from each probe were sent to a high fidelity pen-recorder through a pulse height analyzer and a rate meter. The RCG was recorded with a time constant of 0.4 $\sec$ for the first 40 seconds, and with that of 4 $\mathrm{sec}$ for a few minutes during the equilibrium ( 7 minutes after injection). Venous blood was withdrawn to measure the CBV from the opposite arm of the injection side.

Calculation: As discussed above, the analog computer analysis of a RCG gives the absolute values of the shunt ratio(s) and the mean transit times. In this study, the PBF calculated by $\left[1-\left(1-k^{\prime \prime}+k k^{\prime \prime}\right) \cdot k^{\prime}\right] \cdot F$, was equal to $F$ because no intracardiac shunt was detected $\left(k=k^{\prime}=0\right)$ in any patient. The SBF, $(1-k) \cdot(1-k$ ") $) \cdot F$, was equal to $(1-k$ "). $F$ in the same manner. The $\mathrm{PBF}$ and SBF in usual expression were then as follows:

$$
\begin{aligned}
\operatorname{PBF}(1 / \mathrm{min}) & =60 \times \mathrm{F} / 1000=0.06 \times \mathrm{F} \\
\operatorname{SBF}(1 / \mathrm{min}) & =60 \times\left(1-\mathrm{k}^{\prime \prime}\right) \cdot \mathrm{F} / 1000 \\
& =0.06 \times\left(1-\mathrm{K}^{\prime \prime}\right) \cdot \mathrm{F}
\end{aligned}
$$

The RHV and LHV were calculated from equations (11).

$\operatorname{RHV}(m l)=(1-k \prime) \cdot F \cdot T_{r}$

$\operatorname{LHV}(\mathrm{ml})=\mathrm{F} \cdot \mathrm{T}_{1}$

Cardiac catheterization: Right heart catheterization was performed in all patients. Cournand's $6 \mathrm{~F}$ or $7 \mathrm{~F}$ catheter was passed from PA to Ao through PDA in 20 patients. Left heart catheterization was added to make sure of the angiographical findings in the rests.

Flow calculations were made by the following equations according to the Fick's principle:

$\operatorname{PBF}(1 / \mathrm{min})$

$$
=\frac{\text { oxygen consumption }(\mathrm{ml} / \mathrm{min}) / 10}{\left[\mathrm{O}_{2}(\mathrm{Ao})-\mathrm{O}_{2}(\mathrm{PA})\right](\mathrm{Vol} \%)}
$$

$\operatorname{SBF}(1 / \mathrm{min})$

$$
=\frac{\text { oxygen consumption }(\mathrm{ml} / \mathrm{min}) / 10}{\left[\mathrm{O}_{2}(\mathrm{Ao})-\mathrm{O}_{2}(\mathrm{SIVC})\right](\mathrm{Vol} \%)} \ldots
$$

Shunt ratio $=(\mathrm{PBF}-\mathrm{SBF}) / \mathrm{PBF}$

Where $\mathrm{O}_{2}(\mathrm{PA})$ means the average of the oxygen contents in the main PA and its right and left branches; $\mathrm{O}_{2}(\mathrm{AO})$ is an oxygen content in Ao, and $\mathrm{O}_{2}$ (SIVC) is that of mixed venous blood and is equal to $0.4 \times \mathrm{O}_{2}(\mathrm{SVC})+0.6 \times \mathrm{O}_{2}(\mathrm{IVC})$. Oxygen consumption was measured by Scho- 


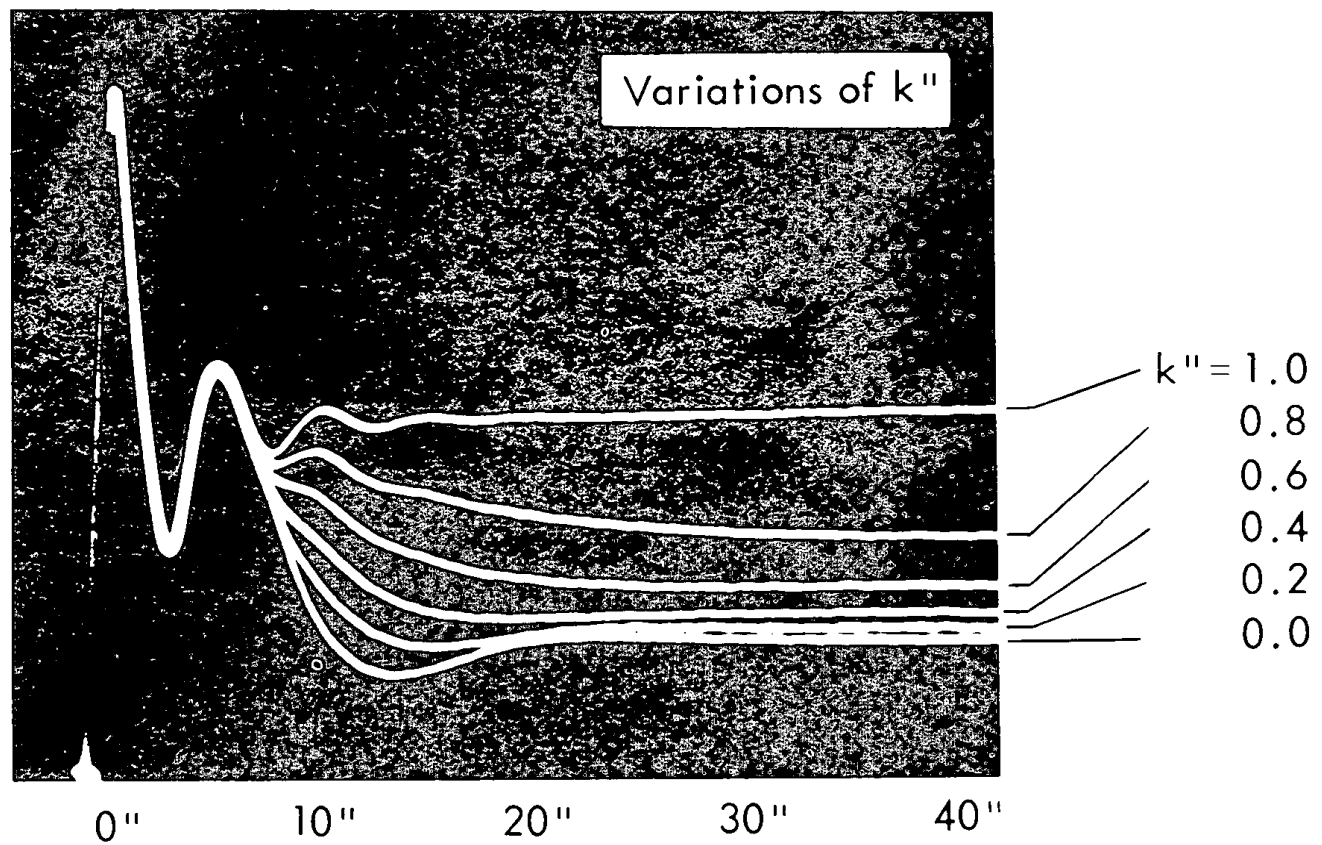

Fig.5. RCG changes with variations in k".

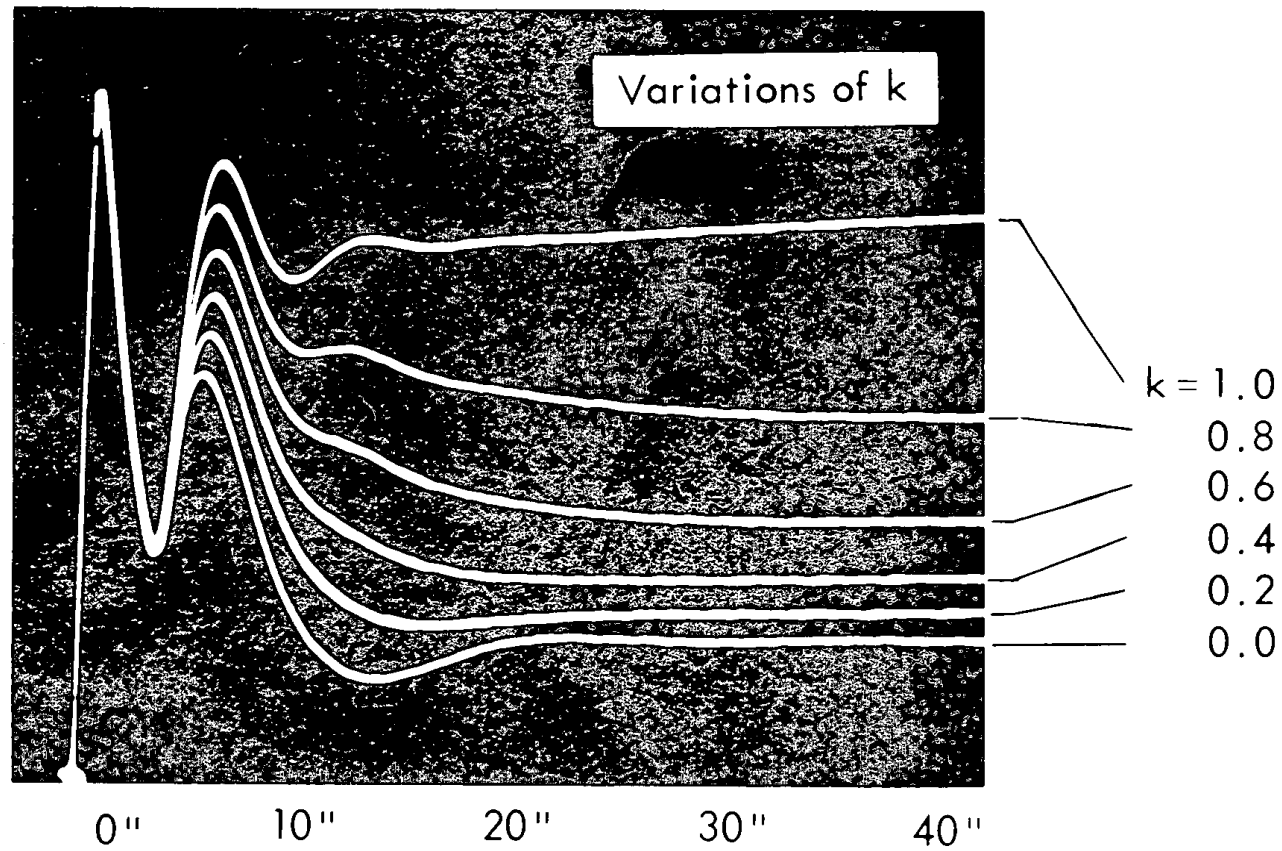

Fig.6. RCG changes with variations in $\mathrm{k}$.

lander's method. Significant pulmonary regurgitation was recognized in one patient by pulmonary arteriography.

Echocardiography: M-mode echocardiograms at the left ventricular (LV) level were recorded on strip chart papers. The LV end-diastolic dimension was measured at the $R$ wave peak of the electrocardiogram, and the LVEDV was calculated by Teichholtz's formula! 12

\section{RESULTS}

(1) Theoretical curves

The theoretical RCGs derived from the analog simulation with variations in $k$ " and $k$ are shown in Figs. 5 and 6, respectively. Variations in the extracardiac shunt ratio ( $k$ "), when all other parameters remain constant, show "shunt waves" of two-thirds the height in the down slope 


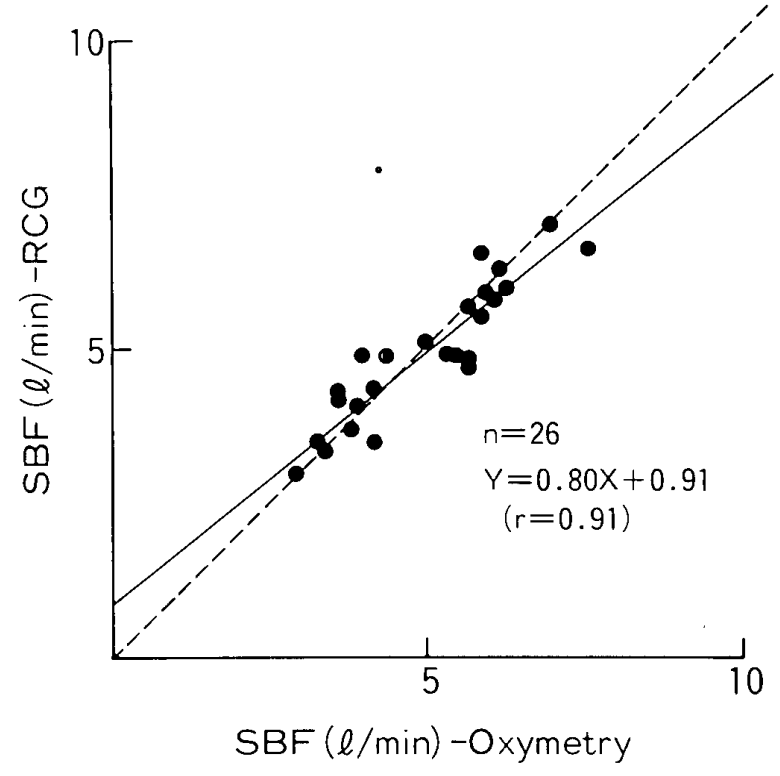

Fig.7. SBF calculated by RCG and oxymetry.

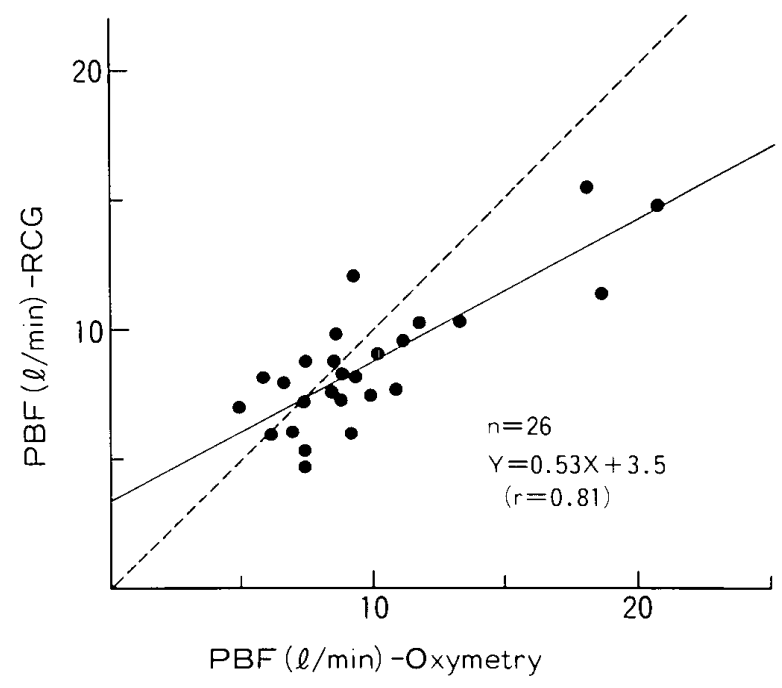

Fig. 8. PBF calculated by RCG and oxymetry.

shoulder of the second hump. This pattern change starts at the time point expected by $\mathrm{T}_{\mathrm{r}}+\mathrm{T}_{\mathrm{l}}+2 \mathrm{~T}_{\mathrm{p}}+2 \tau_{\mathrm{p}}$. An increment in $\mathrm{k}$ " produces a slower down slope and if $\mathrm{k}$ " is greater than 0.6, the third hump, representing a shunt flow to the left side of the heart, becomes apparent.

On the other hand, the effects of the intracardiac shunt ratio $(\mathrm{k})$ appear on the upstroke of the second hump at the time point of $\mathrm{T}_{\mathrm{r}}+\mathrm{T}_{\mathrm{p}}+\tau_{\mathrm{p}}$. The second hump becomes higher and smoother with an increase in $\mathrm{k}$, indicating a prolongation of the mean transit time in the heart.

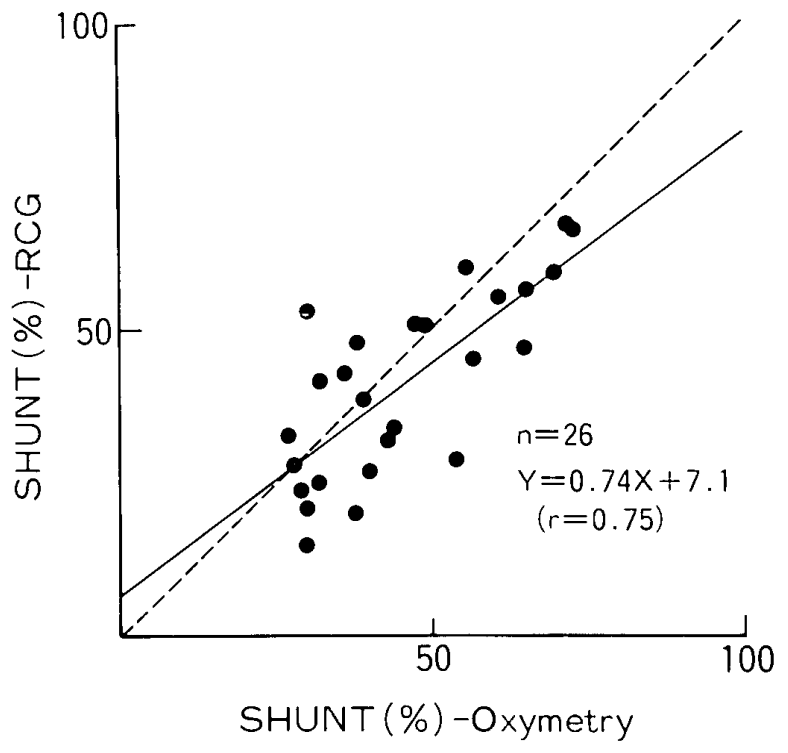

Fig.9. Relation between shunt ratios measured by RCG and oxymetry.

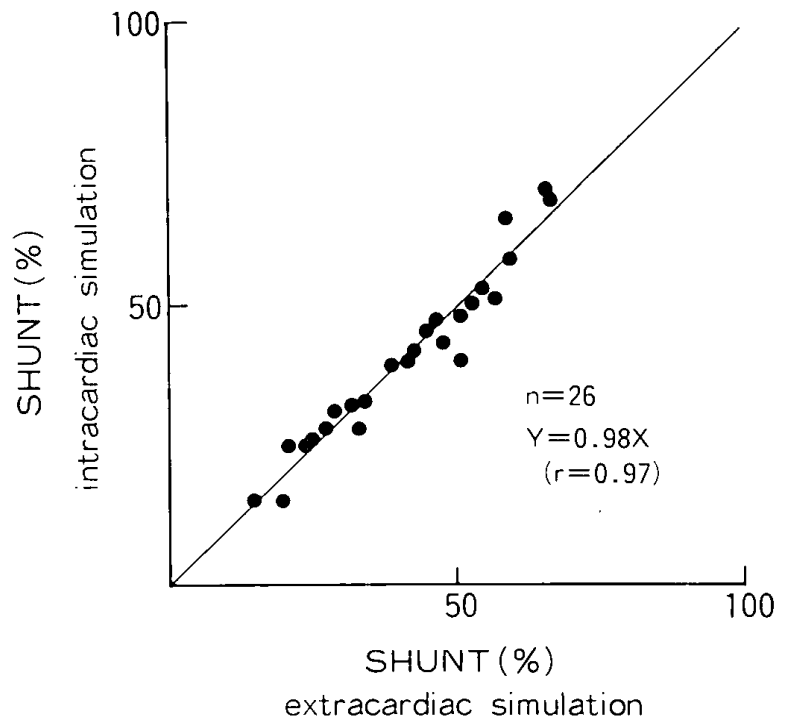

Fig.10. Relation between shunt ratios analyzed idenpendently by intra- and extracardiac shunt circuits.

(2) Clinical application

First of all, the SBF, PBF, and shunt ratio were compared between the two measurements on the bases of both the revised RCG and oxymetry. Figure 7 shows a close agreement $(\mathrm{Y}=0.80 \mathrm{X}+0.91, \mathrm{r}=0.91)$ in the SBF, which is almost perfect in the clinical sense when considering that both methods are liable to primary technical errors and that these studies were not done simultaneously. The PBF values, however, tended to be exaggerated by oxymetry especially 


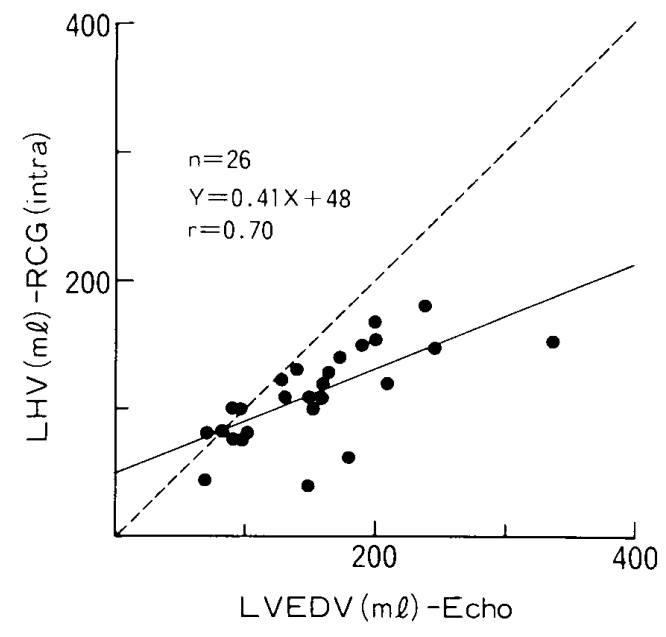

(a) intracardiac shunt simulation

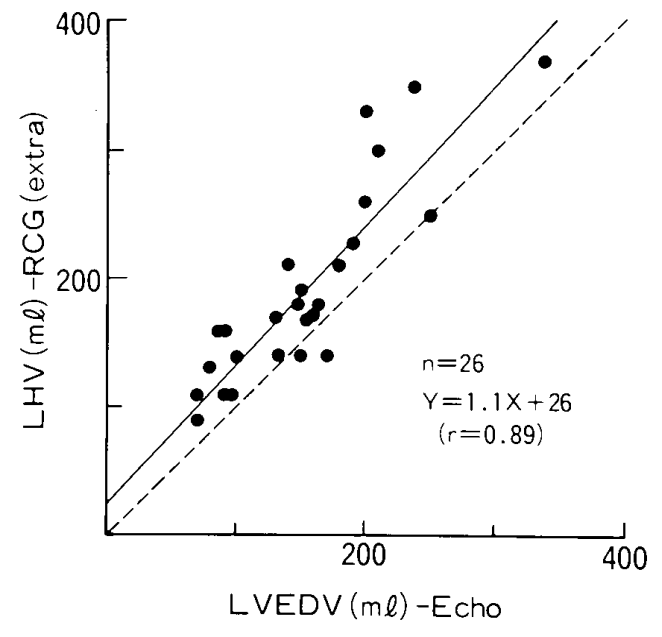

(b) extracardiac shunt simulation

Fig.11. Relation between LHV (RCG) and LVEDV (Echo).

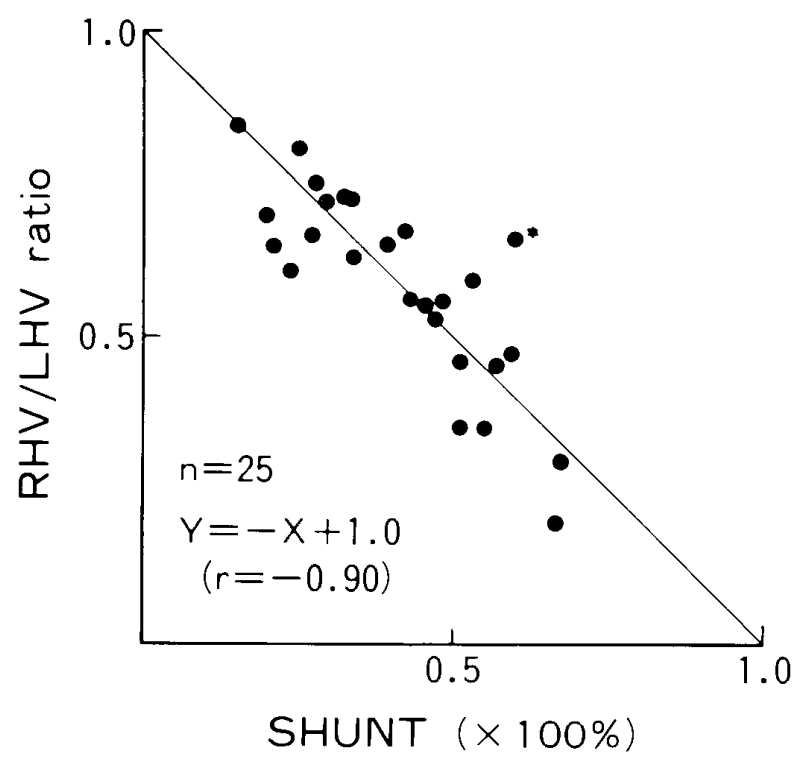

Fig.12. Relation between PDA shunt and RHV/ LHV ratio. The solid line shows the theoretical relation between the two parameters.

in the high PBFs $(Y=0.53 X+3.5, r=0.81$ in Fig. 8). Moreover, the oximetrically calculated shunts were generally larger than those of obtained directly by RCG and the correlation between the two was not neccessarily $\operatorname{good}(\mathrm{Y}=$ $0.74 X+7.1, r=0.75$ in Fig. 9).

Secondly, the improvement offered by the revised models was examined. The RCG shunts were measured independently by the previous intracardiac and the revised extracardiac shunt models. The regression of the two analyses coincided completely $(\mathrm{Y}=0.98 \mathrm{X}, \mathrm{r}=0.97$ in Fig. 10). This revealed that the two simulations are equivalent for shunt evaluation.

Next, regarding the improvement in estimating LHVs, the revised models were compared with the echocardiographic LVEDV. The relation between them is illustrated in Fig. 11 . While the smaller LHVs had been observed in the previous shunt estimation ( $\mathrm{Y}=0.41 \mathrm{X}+48, \mathrm{r}=$ 0.78 in Fig. 11-a), a good correspondence was obtained by the revised circuit $(\mathrm{Y}=1.1 \mathrm{X}+26$, $r=0.89$ in Fig. 11-b). The LHVs seen increased by about $40 \mathrm{ml}$ on the average are accounted for by the fact that they contained left atrial and ventricular volumes.

Figure 12 shows the relationship between the PDA shunt and the ratio of the right-to-left heart volume (RHV/LHV): The larger the shunt ratio, the smaller the RHV/LHV $(r=-0.90)$. The regression line, $\mathrm{Y}=-\mathrm{X}+1.0$, is the same as that calulated theoretically. In case of pulmonary regurgitation (denoted by an asterisk) whose RHV was easily suspected to be increased, the RHV/LHV showed a larger value than would be expected from the shunt estimation only. This exceptional instance was omitted from the statistical analysis of this shunt-RHV/LHV relation*

* In other figures, pulmonary regurgitation does not have statistical effects and the objects of the statistics were all 26 cases. 


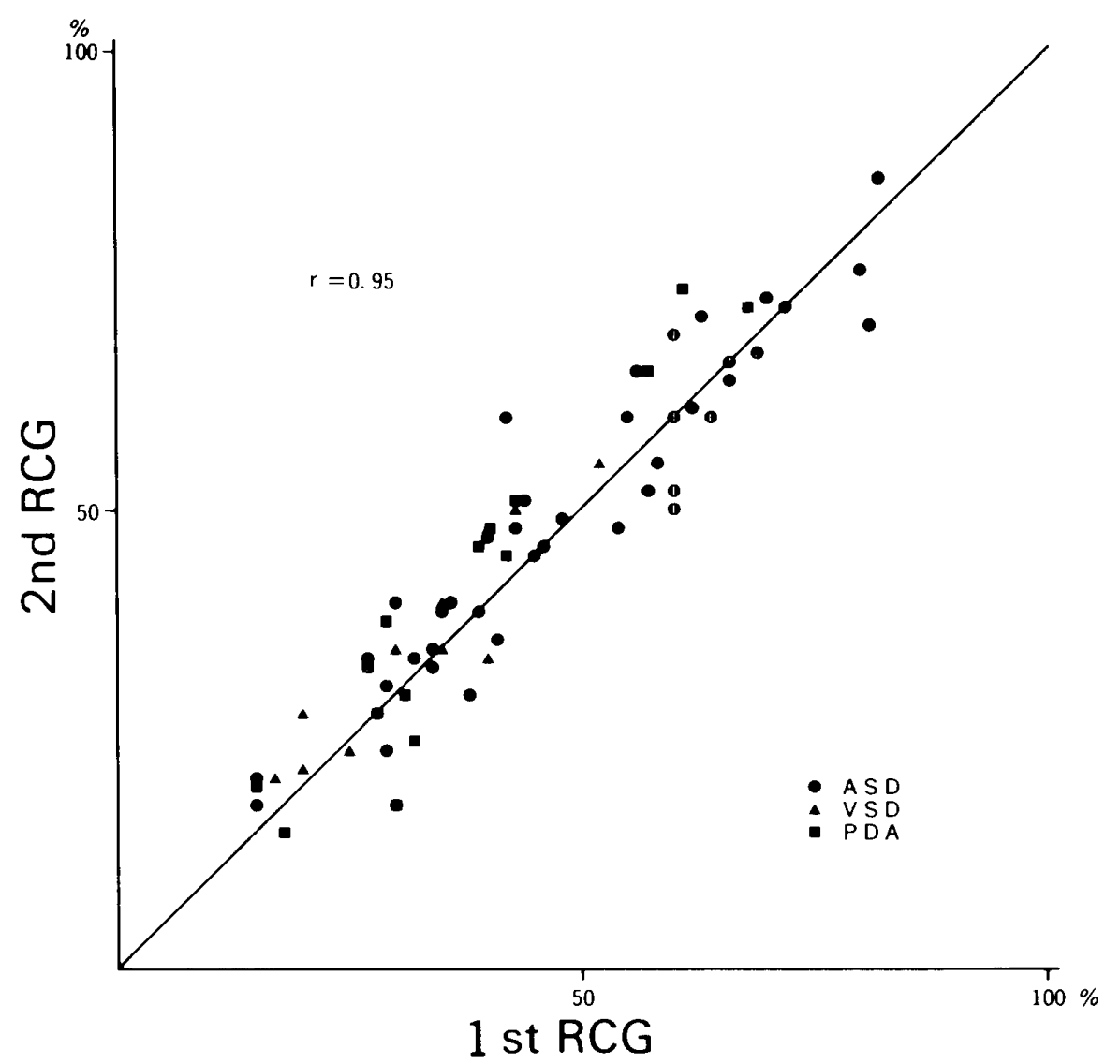

Fig.13. Reproducibility of RCG shunts.

\section{DISCUSSION}

In quantitating cardiac shunts, the use of various radionuclide tracers has been given increasing application. Their great value lies in the non-invasive approach in the estimation of intracardiac shunts; however, the results of this approach leaves much to be desired, especially in PDA, because the shunt flow through the PDA is not equal in both lungs, and that these techniques can not measure its average value. The analytical models hitherto used in the analog computer simulation of RCG have been revised in this study to provide a unique non-invasive way to estimate PDA shunts.

We found that with formerly estimated shunts, the data did not always coincide between the RCG and oxymetric measures and that the SBF showed a good agreement but that the PBF differed. It is obvious that this may reflect true hemodynamics; the shunting flow is not always mixed completely in the PA and its branches and the blood oxygen contents may vary from place to place. It has already been reported that in the measurements of right heart oxygen content variations were to be found even in normal subjects, ${ }^{13-16}$ and the special attention should be paid to the diagnostic blood oxygen determination! ${ }^{17}$ In spite of our efforts in measuring the average oxygen content, we tended to obtain higher values probably influenced by the jet flow of shunting blood.

On the other hand, oxymetric SBF, offering less problem due to incomplete mixing, corresponded more closely to our RCG. We obtained similar evidences in our flow studies on atrial and ventricular septal defects (ASD and VSD).

Our method is easily replicated as shown in Fig. 13. Repeated RCGs in the same 70 individuals with PDA, ASD, or VSD, including those who did not undergo cardiac catheterization, showed a maximum variation in the shunt ratio of $4.7 \%$ and the correlation coefficient was 0.95 . Though we cannot evaluate the reproducibility of the Fick method because of its invasive maneuver, which does not permit repeated examination, it may be safely said that RCG has an excellent reproducibility. A sample case of PDA (a 22 year old male) is illustrated in Fig. 14. His first RCG (above) revealed a $48 \%$ L-R shunt 

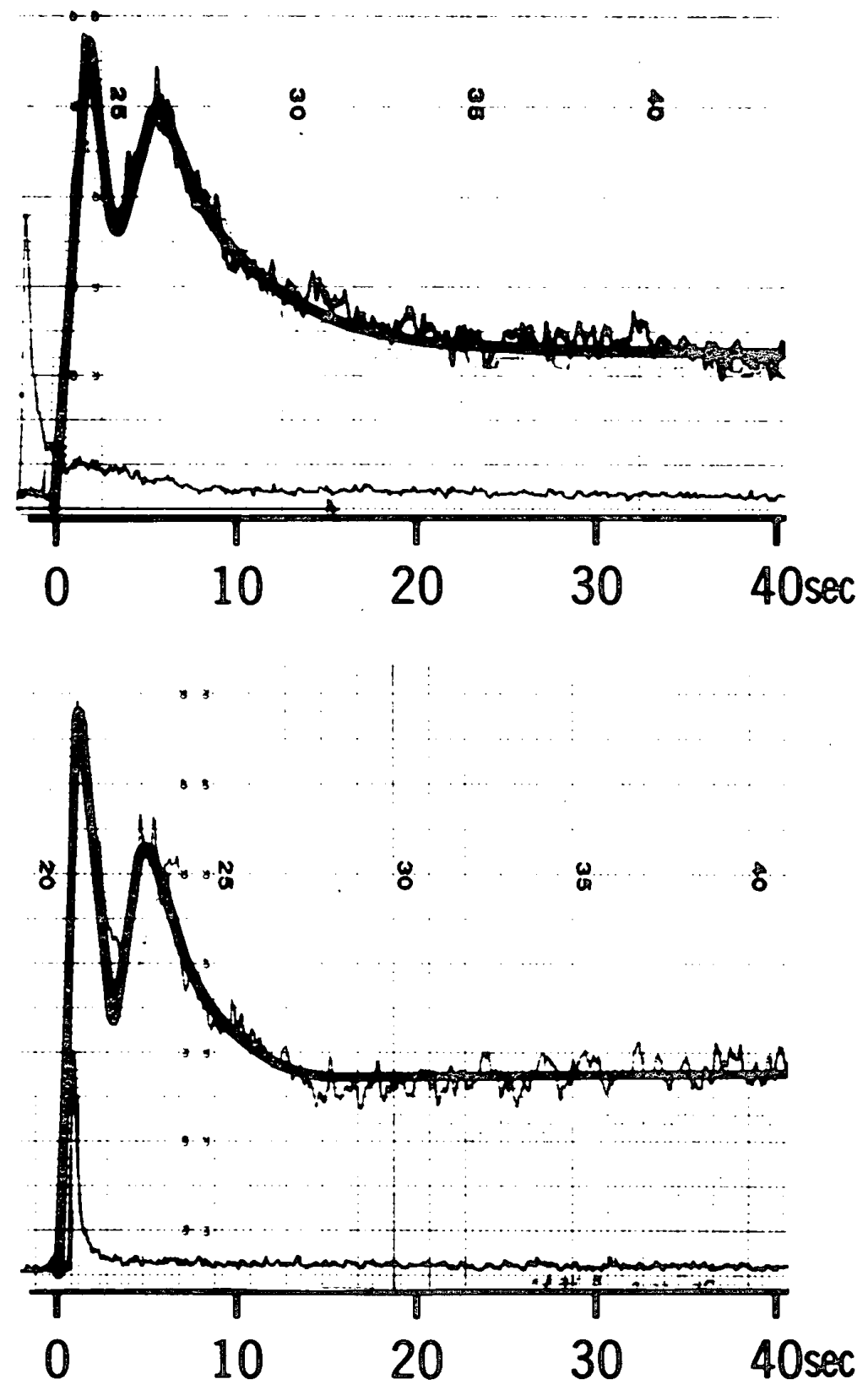

Fig.14. RCGs of patient with PDA, 22 year-old male. The simulated curves (solid lines) are superimposed on the recorded ones. The first (above) and second (below) RCGs measured $48 \%$ and $44 \%$ L-R shunts, respectively. (At a grance, the latter seems to have a significantly smaller shunt because of an ideal injected bolus).

which was significantly larger than the $32 \%$ of shunt calculated by oxymetry. The RCG examined 9 days after catheterization (below) measured a $44 \%$ shunt. It is not unusual to encounter such a discrepancy, while the repeated RCGs present stable results.

Thus, a RCG which deals with mean blood flows must represent a higher fidelity of the flow dynamics in patients with PDA.

Hitherto, in the absence of an extracardiac shunt circuit, PDA has been conveniently analyzed by the intracardiac shunt circuit. The evaluation of shunts themselves was reliable as shown in Fig. 7; however, the calculated LHVs turned out to be unexpectedly low (Fig. 11-a). This can be explained by the fact that the second 
hump of the RCG, which actually represents a transportation of radionuclide through the left heart alone $\left(\mathrm{F} \cdot \mathrm{MTT}_{1}\right)$, is regarded as a passage of tracer through the left heart plus the right heart $\left(\mathrm{F} \cdot \mathrm{MTT}_{1}{ }^{\prime}+\mathrm{k} \cdot \mathrm{F} \cdot \mathrm{MTT}_{\mathrm{r}}{ }^{\prime}\right)$ when an intracardiac shunt simulation is done. That is,

$$
\mathrm{F} \cdot \mathrm{MTT}_{1}=\mathrm{F} \cdot \mathrm{MTT}_{1}{ }^{\prime}+\mathrm{k} \cdot \mathrm{F} \cdot \mathrm{MTT}_{\mathrm{r}} \text {. }
$$

Where the apostrophy(') represents the apparent value obtained by an intracardiac shunt simulation. Then,

$$
\mathrm{LHV}=\mathrm{LHV}^{\prime}+\mathrm{k} \cdot \mathrm{RHV} \text {. }
$$

Accordingly,

$$
\mathrm{LHV}^{\prime}=\mathrm{LHV}-\mathrm{k} \cdot \mathrm{RHV}^{\prime} \text {. }
$$

Thus, the mean left heart volume (LHV'), calculated by an intracardiac shunt simulation in PDA, becomes smaller than expected.

A circuit for PDA shunts was newly introduced to our model. Using this revised model we are now able to measure LHV in a reasonable correlation with echocardiographic LVEDV. It may be controversial to compare the mean LHV directly with the LVEDV since the former contains both the atrial and ventricular volumes. The merit, however, is the fact that we can easily make a quantitative estimation of volume overload to the left heart by this method.

In this simulation study the RHV/LHV ratio of PDA was found to become smaller as the shunt ratio increased. Although the present finding seems reasonable, it could not be verified until we had found a practical technique whereby we could obtain the right and left heart volumes simultaneously. The RHV/LHV and shunt ratios have a negative linear relation theoretically as shown in Fig. 12. Patients with PDA having no other complications are usually located near the theoretical line. If the dot is plotted far away from this line, the patient probably suffers a complicating condition in addition to the PDA, as examplified by the case combined with pulmonary regurgitation.

The analog computer simulation method of $\mathrm{RCG}$ is the only non-invasive way to quantify the average $\mathrm{PBF}, \mathrm{SBF}$, and shunt flow at the same time. Moreover, it can estimate not only the CBV but also the MTTs and blood volumes in the four main compartments of the circulatory system. The clinical application of this method to other congenital heart diseases has been previously described by SAITO et al.

In spite of these merits, there is one limitation of this technique: A complete distinction between the intra- and extra-cardiac shunts is almost impossible. Theoretically, there should be different patterns as illustrated in Figs. 5 and 6. But in actual recordings, the two are so similar that we can hardly separate one from the other. Therefore, the simulation of RCG should be carried out with the aid of clinical information regarding the site of the shunt.

\section{Acknowledgements}

The author expresses sincere gratitude to Professor Chuichi Kawai of the Third Division of Internal Medicine, and to Professor Akina Hirakawa of the Department of Biomedical Information Science, Kyoto University Hospital, for their helpful advice and criticism. He is also grateful to Professor Michiyoshi Kuwahara of the Department of Technology, Kyoto University, for his technical suggestions.

\section{REFERENCES}

1. ALAZRAKI NP, ASHBUUN WL, HAGAN A, FRIEDMAN WF: Detection of left-to-right cardiac shunts with the scintillation camera pulmonary dilution curve. $J$ Nucl Med 13: 142, 1972

2. MALTZ DL, TREVES S: Quantitative radionuclide angiocardiography: Determination of Qp:Qs in children. Circulation 47: 1049, 1973

3. ANDERSON PAW, JONES RH, SABISTON DC Jr: Quantitation of left-to-right shunts with radionuclide angiography. Circulation 49: 512, 1974

4. ALDERSON PO, JOST RG, STRAUSS AW, BOONVIST S, MARKHAN J: Radionuclide angiocardiography: Improved diagnosis and quantitation of left-to-right shunts using area ratio techniques in children. Circulation 51: 1136, 1975

5. TREVES S, COLLINS-NAKAI RL: Radioactive tracers in congenital heart diseases. Am $J$ Cardiol 38: 711,1976

6. SAITO M, MOTOHARA S, HIRAKAWA A, OGINO K, TAKAYASU $M$, KUWAHARA $M$ : Determination of intracardiac shunts in patients with congenital heart diseases by means of analog simulation of radiocardiogram. Jap Circul J 37: 1,1973

7. KUWAHARA M, HIRAKAWA A, KINOSHITA M, SAITO M, NOHARA Y, TAKAYASU M: Analysis of radiocardiogram by analog computer simulation. Int J Biomed Engng 1: 13, 1972

8. SAITO $\mathrm{M}$ : Circulating blood volume and its distribution in the heart, lung, and body in normal subjects and cardiac patients determined by analog simulation of radiocardiogram. Jap Circul $J$ 38: 305,1975

9. MATSUMURA T, HIRAKAWA A, KAWAI C: The Determination of Normal Ranges in RCG parameters. The Heart 10: 561, 1978 (in Japanese)

10. KINOSHITA $\mathrm{M}$, KATO $\mathrm{S}$, MOTOMURA $\mathrm{M}$, KAWAKITA S: Evaluation of $99 \mathrm{~m}$-Tc-albumin dilution curve with simultaneous injection of 99m-Tc- and 131-I-albumins. Jap Circul J 43: 153 , 1979

11. ORDENDORF WH, KITANO M, SHIMIZU S: Evaluation of a simple technique for abrupt intra- 
venous injection of radioisotope. $J$ NuCl Med 9: 205,1965

12. TEICHHOLTZ LE, KREULEN T, HERMAN MV, GORLIN R: Problems in echocardiographic volume determinations: Echocardiographicangiographic correlation in presence or absence of Asynergy. Am J Cardiol 37: 7, 1976

13. COURNAND A, RILEY RL, BREED EF: Measurement of cardiac output in man using the technique of catheterization of the right auricle or ventricle. J Clin Invest 24: 106, 1945

14. DEXTER L, HAYNES FW, BURWELL CS, SAGERSON RP, EVANS JM: Studies of congenital heart diseases. II. The pressure and oxygen content of blood in the right auricle, right ventricle, and pulmonary artery in control patients, with observations on the oxygen saturation and source of pulmonary "capillary" blood. J Clin Invest 26: 554,1947

15. BARRET-BOYES BF, WOOD EH: The oxygen saturation of blood in the venae cavae, right-heart chambers, and pulmonary vessels of healthy subjects. J Lab Clin Med 50: 93, 1957

16. THAYSSEN P, KLARHOLT E: Relation between caval and pulmonary oxygen saturation in children. Br Heart J 43: 574, 1980

17. ANTMAN EM, MARSH JD, GREEN AH, GROSSMAN W: Blood oxygen measurements in the assessment of intracardiac left-to-right shunts: A clinical appraisal of methodology. Am J Cardiol 46: 265,1980 